\title{
Evaluation of three dietary assessment methods and serum biomarkers as measures of fruit and vegetable intake, using the method of triads
}

\author{
Lene Frost Andersen ${ }^{1} *$, Marit Bragelien Veierød ${ }^{1,2}$, Lars Johansson $^{3}$, Amrit Sakhi $^{1}$, Kari Solvoll ${ }^{1}$ and \\ Christian Andre Drevon ${ }^{1}$ \\ ${ }^{1}$ Department of Nutrition and ${ }^{2}$ Department of Medical Statistics, Institute of Basic Medical Sciences, University of Oslo, PB 1046 \\ Blindern, N-0316 Oslo, Norway \\ ${ }^{3}$ Directorate for Health and Social Affairs, Department for Nutrition, Oslo, Norway
}

(Received 23 February 2004 - Revised 11 November 2004 - Accepted 19 November 2004)

\begin{abstract}
The validity of fruit and vegetable intake estimated by $14 \mathrm{~d}$ weighed records, a twenty-seven-item food frequency questionnaire (FFQ) and a 180 -item FFQ was investigated using serum carotenoids as the validity criterion. In addition, the method of triads was used to assess the validity of fruit and vegetable intake estimated from the FFQ and serum carotenoids. One hundred Norwegian men completed $14 \mathrm{~d}$ weighed records and the 180-item FFQ. Eighty-six of them also completed the twenty-seven item FFQ. The partial correlation coefficients between serum carotenoids and fruit and vegetable intake were slightly higher for the $14 \mathrm{~d}$ weighed records than for the two FFQ, but no difference was observed between the 180- and the twenty-seven item FFQ. The strongest correlations were observed between vegetable intake and serum $\alpha$-carotene. The highest validity coefficients (VC) were observed for vegetable intake estimated from weighed records, the 180-item FFQ, the twenty-seven item FFQ and by the biomarker serum $\alpha$-carotene, with VC of $0 \cdot 77,0 \cdot 58,0 \cdot 51$ and $0 \cdot 67$, respectively. In conclusion, the short FFQ gave as valid estimates for fruit and vegetable intake as the long FFQ. Both the estimated partial correlation coefficients and VC suggest that serum $\alpha$-carotene is the best biomarker for intake of vegetable alone and total intake of fruit and vegetables in this population of Norwegian men, but the biomarkers did not perform any better than the FFQ.
\end{abstract}

Fruit: Food frequency questionnaire: Method of triads: Validation: Vegetable

Accurate measurements of an individual's intake of fruit and vegetables are needed for epidemiological studies and to evaluate the fruit and vegetable intervention programmes implemented in many countries. Traditionally, intake of fruit and vegetable has been estimated by use of food frequency questionnaires (FFQ), dietary records and dietary recalls. Due to the errors associated with traditional dietary assessment methods, use of biomarkers, both in validation studies and as measures of intake, has been a recent and important addition to the field. Data from controlled feeding studies in human subjects suggest that plasma carotenoids may be potential biomarkers for intake of fruit and vegetables (Jensen et al. 1985; Kim \& Simphson, 1988; Brown et al. 1989; Micozzi et al. 1992; Bowen et al. 1993; Martini et al. 1995; Yeum et al. 1996; Broekmanns et al. 2000). However, plasma concentrations of carotenoids are correlated with factors other than the intake, such as age, BMI, physical activity, plasma concentration of triacylglycerols and cholesterol (Olmedilla et al. 1994; Forman et al. 1995; Brady et al. 1996; Kitamura et al. 1997; Rock et al. 1997) and may not necessarily be better than traditional dietary assessment methods to evaluate intake of fruit and vegetables.

Both traditional dietary assessment methods and biomarkers need to be validated. Kaaks (1997) has recommended the method of triads for validity studies where data from a questionnaire, a reference method and a biomarker are available. By this method, a validity coefficient (VC) expressing the correlation between observed intake and an individual's unknown true intake can be estimated for each of the three methods. The three observed pair-wise correlations between the FFQ, the reference method and the biomarker form the basis for calculation of the VC. The method of triads has been used by other authors for validation of nutrient intake estimated from FFQ and for validation of biomarkers for intake of different nutrients (Kaaks, 1997; Ocke \& Kaaks, 1997; Kabagambe et al. 2000; Fowke et al. 2002; Pufulete et al. 2002). To our knowledge only one study has been published using the method of triads to validate intake of foods and biomarkers for food intake (Fowke et al. 2002).

In the present study of healthy Norwegian men, we examined the association between serum carotenoid concentration and three methods for assessment of fruit and vegetable intake; a twentyseven-item FFQ, a 180-item FFQ and $14 \mathrm{~d}$ weighed records. The method of triads was applied to validate fruit and vegetable intake estimated from the twenty-seven-item FFQ and the 180-item FFQ, and serum concentration of carotenoids as a biomarker for intake of fruit and vegetables.

\section{Materials and methods}

Healthy men working at Ørland air force station, a military station located on the coast in mid-Norway, were invited to participate 
in the study. Men using cholesterol-lowering drugs were not included. The study was conducted in autumn 1995 and winter 1996 (Andersen et al. 1999).

A 180 -item FFQ was mailed to 137 men at the beginning of the study. About 1 week later they returned the FFQ, a blood sample was collected and they were instructed on how to keep weighed food records for $14 \mathrm{~d}$. Within 2 weeks after filling in the FFQ, participants started to record their food intake. A total of 125 participants completed both the records and the 180-item FFQ. The twenty-seven item FFQ was filled in 1.5-2 months after the 180-item FFQ and the weighed records. The twenty-seven item FFQ was completed by 109 of the 125 participants. Serum carotenoid concentration was analysed from 112 participants. Dietary intake data from the weighed records and the 180-item FFQ and serum concentration of carotenoids are available for 100 individuals. Moreover, we have dietary data from the twenty-seven item FFQ, weighed records and serum carotenoid data for eighty-six participants.

The regional ethical committee approved the study protocol, and all participants gave written informed consent.

\section{The 180-item food frequency questionnaire}

The eleven-page optical mark readable questionnaire was designed to capture the habitual food intake among adults during the last year. The FFQ included questions about 180 food items grouped together according to the Norwegian meal pattern. The questionnaire included eight questions about vegetable intake (vegetables used as bread spread, carrot, cabbage, sauerkraut, swede, 'cauliflower, broccoli, Brussels sprouts', 'peas, frozen vegetables', green salads) and eight questions about fruit intake (fruit used as bread spread, orange juice, 'other juices', apple, citrus, 'other fruits', berries, canned fruits). Frequency alternatives vary from once per month to several times per $\mathrm{d}$, and the portion sizes are given as household units, e.g. glasses, pieces, decilitre. Portion sizes in household measures were converted into grams using Norwegian standard portion sizes (Blaker \& Aarsland, 1989). The amount of fruit and vegetables consumed was calculated as frequency (in times per d) times portion size (in grams). The selection of vegetable and fruit items included in the questionnaire was based on data from earlier dietary surveys among Norwegian adults (Solvoll et al. 1985; Blaker et al. 1988). The questionnaire also includes questions about frequency of use and portion size of seven types of dietary supplements (cod liver oil, cod liver oil and fish oil capsules, multivitamin/mineral mixtures, vitamin C, vitamin $\mathrm{E}$ and $\mathrm{Fe}$ ). A detailed description of the questionnaire is found elsewhere (Nes et al. 1992).

\section{The 27-item food frequency questionnaire}

The twenty-seven item FFQ included seven questions about intake of orange juice, carrot, cabbage/broccoli, other vegetables, apple/pears, citrus fruit, and other fruits. For orange juice, we asked for the number of glasses per week, whereas the unit was times per week for the other vegetables and fruits. The frequency scale is never, $<1,1-2,3-4,5-6,7-8,9-10, \geq 11$. The participants were asked to consider their usual dietary habits during the last year when filling in the questionnaire. The questionnaire also included questions about frequency of use of two types of dietary supplements (cod liver oil and multivitamin/mineral mixtures).
More details about the 27-item questionnaire have been published elsewhere (Andersen et al. 2002).

\section{Weighed diet records}

The $14 \mathrm{~d}$ weighed diet records were split into five periods $(3+3+3+3+2 \mathrm{~d}$ units) by 1 -week intervals. The total $14 \mathrm{~d}$ period consisted of 10 weekdays (two Mondays, two Tuesdays etc.) and 4 weekend days (Andersen et al. 1999).

Participants were provided with blank diary forms and a digital balance with a precision of $\pm 1 \mathrm{~g}$ and a maximum capacity of $2500 \mathrm{~g}$. They were given both oral and written instructions on how to weigh and describe in detail the consumption of foods and beverages, and how to fill in the diary forms. Furthermore, the subjects were asked to monitor their usual food intake and to avoid any temptation to change the diet in order to lose weight or simplify the recording. The use of household measures was accepted when it was impossible to use the balance.

The diary form from the first $3 \mathrm{~d}$ period was checked for completeness immediately after finishing this first period. All participants were contacted by phone before starting the second recording period and improper responses were clarified. Two nutritionists (L.F.A. and K.S.) coded the forms.

\section{Food calculations}

Daily intake of fruit (including fruit juice but not jam and fruit syrup) and vegetables was computed from the $14 \mathrm{~d}$ weighed records and the 180-item FFQ by using a food database and software system developed at the Department of Nutrition, University of Oslo. The food database is mainly based on the official food composition table (Statens ernæringsråd \& Statens næringsmiddeltilsyn, 1995), and is continuously supplemented with data on new food items and nutrients. It was not possible to calculate the carotenoid content of the diet, except for $\beta$-carotene, from the current food database.

\section{Blood samples and analyses}

Blood samples were collected in the morning after an overnight fast. The samples were centrifuged and stored at $-18^{\circ} \mathrm{C}$ for a maximum of $5 \mathrm{~d}$ before transferring to $-70^{\circ} \mathrm{C}$.

Serum concentrations of $\alpha$-carotene, $\beta$-carotene, lycopene, zeaxanthin and lutein were analysed by HPLC. Astaxanthin was used as internal standard and was prepared by dissolving $1 \mathrm{mg}$ astaxanthin in $4 \mathrm{ml}$ benzene $(0.42 \mathrm{~mm})$. We have analysed some plasma samples without adding internal standard and we found no peaks for astaxanthin. Thus, the amount of endogenous astaxanthin in plasma is at least less than $5 \%$ of astaxanthin added as internal standard and should be of minor importance. A $200 \mu \mathrm{l}$ aliquot of serum sample was transferred to a $2 \mathrm{ml}$ amber glass vial and $900 \mu \mathrm{l}$ precipitating solution $(10 \mathrm{ml}$ 2-propanol containing $10 \mathrm{mg} / \mathrm{l}$ butylated hydroxytoluene and $20 \mu 10.42 \mathrm{~mm}$-astaxanthin) were added. The mixture was vortexed for $5 \mathrm{~min}$ and centrifuged for $15 \mathrm{~min}$ at $3000 \mathrm{~g}$ and $4^{\circ} \mathrm{C}$. Supernatant $(100 \mu \mathrm{l})$ was injected into the HPLC system (Hewlett Packard 1100 HPLC, Palo Alto, CA, USA). A Waters pump was used to deliver mobile phase to the analytical column (YMC Carotenoid S5 $\mu \mathrm{m}, 4.6 \times 250 \mathrm{~mm}$ from Waters, Milford, MA, USA) and the detection was performed using a Waters tunable absorbance detector at $453 \mathrm{~nm}$. The mobile phases used were A ( $100 \%$ water), B (30\% acetone 
in absolute ethanol), C (100\% acetone). A gradient elution was used with initial conditions of $10 \% \mathrm{~A}$ and $90 \% \mathrm{~B}$ at flow rate of $2 \mathrm{ml} / \mathrm{min}$. This was immediately followed by a linear increase to $100 \% \mathrm{~B}$ in $5 \mathrm{~min}$ and was held for $5 \mathrm{~min}$. After this, there was a linear increase to $100 \%$ solvent $\mathrm{C}$ in $1.5 \mathrm{~min}$ and was held for $11 \mathrm{~min}$. The system was then returned to initial conditions in $1 \mathrm{~min}$ and was equilibrated for $7 \mathrm{~min}$ before next injection. The temperature was ambient. All the samples were quantified against a three-point calibration curve generated daily.

The recovery was measured by preparing a standard solution containing $0.788 \mu \mathrm{M}$-lutein, $0.785 \mu \mathrm{M}$-zeaxanthin, $0.317 \mu \mathrm{M}-\alpha$-carotene, $0.785 \mu \mathrm{M}-\beta$-carotene and $0.434 \mu \mathrm{M}$-lycopene in $1 \%$ bovine serum albumin solution in PBS and quantified against a calibration curve. The recovery of the five carotenoids was as follows: lutein $(103 \%)$, zeaxanthin $(106 \%), \alpha$-carotene $(100 \%), \beta$-carotene $(108 \%)$ and lycopene $(118 \%)$. The calibration solutions were used for estimation of the linearity of the method. The coefficient of correlation was better than 0.990 for all five carotenoids. The intra-assay reproducibility varied from $3.7 \%$ for lutein to $6.5 \%$ for lycopene $(n 10)$ and the inter-assay reproducibility varied from $5.3 \%$ for zeaxanthin to $9.6 \%$ for lycopene ( $n 10)$. The limit of detection in standard solutions (prepared in the same way as sample) was $0.005 \mu \mathrm{M}$ for $\alpha$-carotene, $0.006 \mu \mathrm{M}$ for $\beta$-carotene, $0.01 \mu \mathrm{M}$ for lutein, $0.013 \mu \mathrm{M}$ for zeaxanthin and $0.04 \mu \mathrm{M}$ for lycopene. We have analysed the National Institute of Standards and Technology (NIST) standard (Standard reference material 968c, http://www. nist.gov) for carotenoids by using our method, and observed that the values of carotenoids in the NIST standard were within the standard deviation of the concentrations given by the supplier.

Pure standards of lutein, $\alpha$-carotene, $\beta$-carotene, lycopene, astaxanthin and butylated hydroxytoluene were supplied by Sigma (St. Louis, MO, USA). Zeaxanthin was obtained from Carl Roth GmbH (Karlsruhe, Germany).

Total cholesterol in serum was measured enzymatically at the Institute of Aviation Medicin, Oslo, by the Cholesterin CHODPAP-Method (Boehringer, Mannheim, Germany). Triacylglycerol was enzymatically analysed using the Triclycerides Enzymatic PAP 150 method of BioMerieux (Lyon, France).

\section{Other data collection}

Height and weight were measured by research staff to the nearest $0.5 \mathrm{~cm}$ and $100 \mathrm{~g}$. Underwear, trousers and stockings were allowed but no shoes.

\section{Statistical analysis}

Sample means, standard deviations and medians are presented for intake of fruit and vegetables and serum concentrations of carotenoids. In all further statistical analyses, dietary intake (fruit and vegetable) and serum carotenoids were $\log _{\mathrm{e}}$ transformed. Paired $t$ test was used to compare fruit and vegetable intake estimated by the weighed record and the 180-item FFQ. Comparisons of carotenoid concentrations between users and non-users of dietary supplements were performed by $t$ tests.

Pearson's correlation coefficients were calculated for the association between fruit and vegetable intake estimated from the questionnaires and the weighed record. Fisher's $Z$ transformation formed the basis for estimation of confidence intervals for the correlation coefficients between questionnaires and weighed record assessments. Partial correlation coefficients adjusted for age, BMI, and serum concentrations of triacylglycerols and cholesterol were calculated for the association between fruit and vegetable intake of the three dietary assessment methods and serum concentration of carotenoids. Partial correlation coefficients adjusted for smoking in addition to the four variables mentioned earlier were also calculated. These partial correlation coefficients were similar to the partial correlation coefficients estimated without adjustment for smoking. The partial correlation coefficients without adjustment for smoking were included in the paper because data about smoking were not available for eleven subjects, and including smoking thereby reduced the sample size.

The method of triads was used to estimate $\mathrm{VC}$ between true intake and intake estimated from the weighed record, the 180or twenty-seven item FFQ and the biomarkers (Kaaks, 1997; Ocke $\&$ Kaaks, 1997) (Fig. 1). Let $Q, R$ and $M$ be the measurements of dietary intake from the FFQ (180- or twenty-seven item FFQ), the weighed record and the biomarker, respectively, and let $T$ denote the true unknown long-term dietary intake. The $\mathrm{VC}$ can be estimated as:

$$
\begin{aligned}
\mathrm{VC}_{Q T} & =\sqrt{\left[\left(r_{Q R} \times r_{Q M}\right) / r_{R M}\right]}, \\
\mathrm{VC}_{R T} & =\sqrt{\left[\left(r_{Q R} \times r_{R M}\right) / r_{Q M}\right]} \\
\text { and } \mathrm{VC}_{M T} & =\sqrt{\left[\left(r_{Q M} \times r_{R M}\right) / r_{Q R}\right]},
\end{aligned}
$$

respectively, where $r$ is an estimated correlation coefficient. We estimated $r_{Q R}$ by Pearson's correlation coefficient, and $r_{Q M}$ and $r_{R M}$ as partial correlation coefficients as described earlier.

This technique assumes that random errors in the dietary assessment methods are uncorrelated and that positive linear correlations exist between estimates obtained by the dietary assessment methods and true intake (Kaaks, 1997; Daures et al. 2000).

Confidence intervals were estimated by empirical percentiles (2.5th and 97.5th) for the replicates of estimated VC from 1000 bootstrap samples (Ocke \& Kaaks, 1997; De Angels \& Young, 1998). A bootstrap sample can produce negative correlations between measurements, and then the $\mathrm{VC}$ cannot

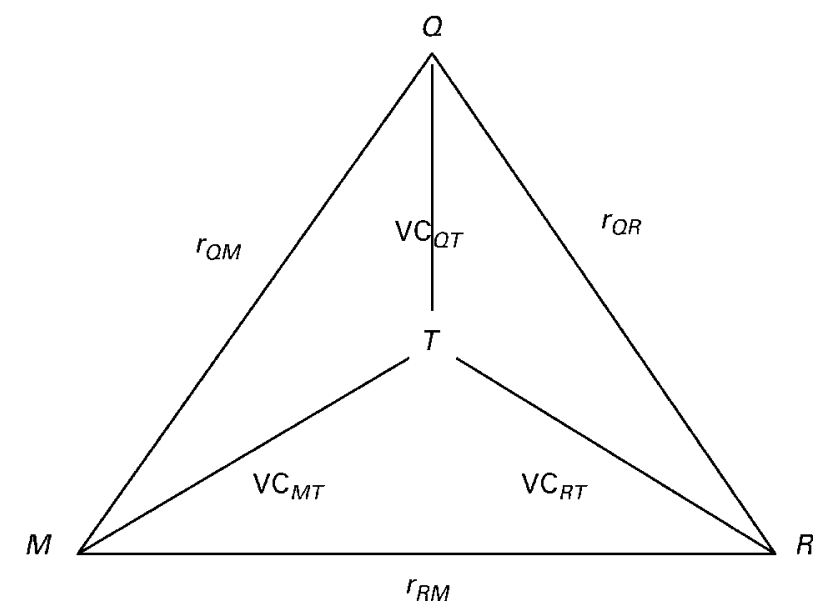

Fig. 1. Illustration of the method of triads used to estimate the validity coefficients $\left(\mathrm{VC}_{Q T}, \mathrm{VC}_{R T}, \mathrm{VC}_{M T}\right)$ between true dietary intake $(T)$ and intake estimated by biomarker $(M)$, food frequency questionnaire (Q; 27- or 180-item) and weighed records $(R) . r_{Q R}, r_{Q M}$ and $r_{R M}$ are correlation coefficients between the different methods (modified after Kabagambe et al. 2000). 
Table 1. Characteristics of the subjects and serum concentration of carotenoids ( $n$ 100)

\begin{tabular}{lccc}
\hline & Mean & SD & Median \\
\hline Age (years) & 36.4 & 9.4 & 38.3 \\
BMI $\left(\mathrm{kg} / \mathrm{m}^{2}\right)$ & 25.5 & 2.8 & 24.8 \\
Current smokers $(n)$ & 16 & & \\
Lutein $(\mu \mathrm{mol} / \mathrm{l})$ & 0.174 & 0.064 & 0.168 \\
Zeaxanthin $(\mu \mathrm{mol} / \mathrm{l})$ & 0.039 & 0.015 & 0.038 \\
Lycopene $(\mu \mathrm{mol} / \mathrm{l})$ & 0.746 & 0.379 & 0.685 \\
$\alpha$-Carotene $(\mu \mathrm{mol} / \mathrm{l})$ & 0.088 & 0.073 & 0.068 \\
$\beta$-Carotene $(\mu \mathrm{mol} / \mathrm{l})$ & 0.449 & 0.230 & 0.379 \\
\hline
\end{tabular}

be estimated. In these situations, the default method is that VC are set to missing values and confidence intervals are estimated from less than 1000 bootstrap samples, leading to inaccurate confidence intervals (Ocke \& Kaaks, 1997). To elucidate this, we have also set missing VC to zero and then calculated empirical percentiles from the total 1000 bootstrap samples. Both confidence intervals are presented.

All the statistical analyses were performed with SPSS 11.0 (SPSS Inc., Chicago, IL, USA), except the bootstrapping where S-PLUS 6.1 was applied. All tests are two-sided and a $5 \%$ level of significance was used.

\section{Results}

The study included 100 healthy men aged $20-55$ years with BMI from 20.5 to $34.1 \mathrm{~kg} / \mathrm{m}^{2}$. Characteristics of the subjects and serum concentrations of carotenoids are presented in Table 1. Only small differences were observed between subjects who used nutritional supplements ( $n$ 26) and subjects who did not use supplements ( $n$ 74) with regard to serum concentrations of the five carotenoids; for serum $\alpha$-carotene supplement users had a serum concentration (mean $(95 \% \mathrm{CI})$ ) of $0 \cdot 108(0 \cdot 066,0 \cdot 159) \mu \mathrm{mol} / \mathrm{l} v$. non-supplement users who had a concentration of $0.082(0.068,0.095) \mu \mathrm{mol} / \mathrm{l}$. The corresponding figures for $\beta$-carotene were $0.487(0.382,0.592)$ $\mu \mathrm{mol} / \mathrm{l} v .0 .436(0.385,0.487) \mu \mathrm{mol} / \mathrm{l}$, for lutein $0.175(0.143$, $0 \cdot 207) \mu \mathrm{mol} / 1$ v. $0.174(0.161,0.188) \mu \mathrm{mol} / \mathrm{l}$, for zeaxanthin $0.037(0.032,0.043) \mu \mathrm{mol} / 1$ v. $0.040(0.036,0.043) \mu \mathrm{mol} / \mathrm{l}$, and for lycopene $0.640(0.556,0.724) \mu \mathrm{mol} / 1$ v. $0.783(0.687,0.880)$ $\mu \mathrm{mol} / \mathrm{l}$.

Intake of fruit and vegetables assessed by the three dietary assessment methods are presented in Table 2. Estimated intake of fruit from the 180-item FFQ was significantly higher than the intake of fruit from the weighed records $(P=0.04)$. There was no significant difference between the two methods with regard to vegetable intake $(P=0 \cdot 29)$.

Pearson's correlation coefficients for fruit and vegetable intake assessed by the 180-item FFQ and the $14 \mathrm{~d}$ weighed record and assessed by the twenty-seven item FFQ and the records are given in Table 3. The correlation coefficients ranged from 0.33 to $0 \cdot 55$, and were all significant $(P<0 \cdot 01)$. The highest correlations were observed between the twenty-seven item FFQ and the weighed record for fruit intake and for total fruit and vegetable intake. The correlations presented are unadjusted coefficients, but adjustments for age and BMI did not change the correlations substantially. The largest change with adjustment was found for the correlation between fruit intake estimated from the weighed record and the twenty-seven item FFQ, where the unadjusted correlation of 0.55 (Table 3 ) increased to 0.57 when adjusting for age and BMI.

Table 4 includes partial correlation coefficients between intake of fruit and vegetables from the three different dietary methods and serum concentrations of carotenoids. In general, the correlation coefficients between intake and serum levels were higher for the $14 \mathrm{~d}$ weighed record than for the two questionnaires. For all three dietary assessment methods, the highest correlations were found between serum $\alpha$-carotene and vegetable intake, and between serum $\alpha$-carotene and total fruit and vegetable intake. In addition, significant correlation coefficients were

Table 2. Intake of fruit and vegetables from the 14-d weighed records (WR) and the two food frequency questionnaires (FFQ)

\begin{tabular}{|c|c|c|c|c|c|c|c|c|c|}
\hline & \multicolumn{3}{|c|}{$\mathrm{WR}^{\star}(n 100)$} & \multicolumn{3}{|c|}{ 180-Item FFQ* (n 100) } & \multicolumn{3}{|c|}{ 27-Item FFQ* $(n 86)$} \\
\hline & Mean & $\mathrm{SD}$ & Median & Mean & $\mathrm{SD}$ & Median & Mean & $\mathrm{SD}$ & Median \\
\hline Fruit intake & 109 & 107 & 78 & 128 & 107 & 100 & 0.9 & 0.6 & 0.7 \\
\hline Vegetable intake $†$ & 108 & 59 & 102 & 115 & 70 & 94 & 0.8 & 0.4 & 0.6 \\
\hline
\end{tabular}

*Unit for WR and 180-item FFQ: g/d; unit for twenty-seven item FFQ: times/d.

$\dagger$ Potatoes are not included.

Table 3. Pearson's correlation coefficients and $95 \%$ confidence intervals comparing fruit and vegetable intake* as estimated by the two food frequency questionnaires (FFQ) and the $14 \mathrm{~d}$ weighed records (WR)

\begin{tabular}{|c|c|c|c|c|}
\hline & \multicolumn{2}{|c|}{ 180-Item FFQ v. WR† ( $n$ 100) } & \multicolumn{2}{|c|}{ 27-Item FFQ $v$. WR† ( $n$ 86) } \\
\hline & Correlation coefficients & $95 \% \mathrm{Cl}$ & Correlation coefficients & $95 \% \mathrm{Cl}$ \\
\hline Fruit intake & 0.33 & $0.14,0.50$ & 0.55 & $0.38,0.68$ \\
\hline Vegetable intake $\ddagger$ & 0.45 & $0.26,0.60$ & 0.39 & $0.19,0.56$ \\
\hline Fruit and vegetable intake $\ddagger$ & 0.42 & $0.25,0.58$ & 0.55 & $0.38,0.68$ \\
\hline
\end{tabular}

*Vegetable and fruit intake were $\log _{\mathrm{e}}$ transformed.

† Unit for WR and 180-item FFQ: g/d; unit for twenty-seven item FFQ: times/d.

$\ddagger$ Potatoes were not included in the vegetable intake. Fruit juices were included in the fruit, volume juice (ml) was expressed in $\mathrm{g}$. 
Table 4. Partial correlation coefficients $\nmid$ between intake of fruit and vegetables $\ddagger$ and serum concentration of carotenoids§

\begin{tabular}{|c|c|c|c|c|c|}
\hline & Lutein & Zeaxantin & Lycopene & $\alpha$-Carotene & $\beta$-Carotene \\
\hline \multicolumn{6}{|l|}{ Weighed records ( $n$ 100) } \\
\hline Vegetables and fruit $(\mathrm{g} / \mathrm{d})$ & $0.22^{*}$ & 0.16 & -0.12 & $0.37^{\star \star \star}$ & $0 \cdot 18$ \\
\hline Vegetables (g/d) & $0.21^{*}$ & 0.15 & -0.05 & $0.52^{\star \star \star}$ & $0 \cdot 26^{\star}$ \\
\hline Fruit $(g / d)$ & 0.13 & 0.03 & -0.12 & 0.16 & 0.13 \\
\hline \multicolumn{6}{|l|}{ 180-Item FFQ ( $n$ 100) } \\
\hline Vegetables and fruit $(\mathrm{g} / \mathrm{d})$ & $0 \cdot 16$ & 0.17 & $0 \cdot 15$ & $0.25^{\star}$ & 0.07 \\
\hline Vegetables (g/d) & 0.13 & $0 \cdot 10$ & $0 \cdot 18$ & $0 \cdot 39^{\star \star \star}$ & 0.09 \\
\hline Fruit $(\mathrm{g} / \mathrm{d})$ & $0 \cdot 11$ & $0 \cdot 16$ & $0 \cdot 10$ & 0.03 & -0.01 \\
\hline \multicolumn{6}{|l|}{ 27-Item FFQ ( $n$ 86) } \\
\hline Vegetables and fruit (times/d) & $0 \cdot 16$ & $0 \cdot 15$ & $0 \cdot 12$ & $0 \cdot 26^{\star}$ & 0.12 \\
\hline Vegetables (times/d) & $0 \cdot 10$ & 0.08 & $0 \cdot 10$ & $0.35^{\star *}$ & 0.07 \\
\hline Fruit (times/d) & 0.17 & 0.11 & $0 \cdot 10$ & 0.13 & 0.14 \\
\hline
\end{tabular}

$F F Q$, food frequency questionnaire.

$\dagger$ Partial correlation coefficients adjusted for total serum cholesterol, serum triacylglycerols, age and BMI.

₹ Potatoes were not included in the vegetable intake. Fruit juices were included in the fruit intake.

$\S$ Vegetable and fruit intake and serum concentration of carotenoids were $\log _{\mathrm{e}}$ transformed.

observed between intake of vegetables from the weighed records and serum concentration of lutein and $\beta$-carotene. Fruit intake was not significantly correlated with any of the carotenoids for the three dietary assessment methods.

The VC for the FFQ, the weighed records and serum concentration of $\alpha$-carotene are presented in Table 5. The observed $\mathrm{VC}$ are relatively high, ranging from 0.51 to 0.77 for the four measurements of vegetable intake, and from 0.43 to 0.91 for measurements of total fruit and vegetable intake. The VC observed for vegetable intake estimated from the weighed records were higher than the VC observed for the FFQ; the VC for weighed records, 180-item FFQ and twenty-seven item FFQ were $0 \cdot 77,0.58$ and $0 \cdot 51$, respectively. The proportion of missing $\mathrm{VC}$ from the bootstrap samples equalled zero or was low.

The VC for the FFQ, the weighed records and serum concentration of $\beta$-carotene, lutein and zeaxanthin are presented in the Appendix. The partial correlation coefficients obtained between the dietary assessment methods and serum concentration of $\beta$-carotene, lutein and zeaxanthin were not significant in most cases. Thus, the observed $\mathrm{VC}$ for serum concentration of $\beta$-carotene, lutein and zeaxanthin are generally lower than for $\alpha$-carotene, and the proportions of missing VC from the bootstrap samples were relatively large, i.e. giving less accurate confidence intervals. In general, these VC were higher both for the weighed records, the 180-item FFQ and the twenty-seven item FFQ than for the biomarkers.

VC for serum lycopene were not estimated because the partial correlation coefficients obtained between the dietary assessment methods and serum lycopene were very low. Furthermore, VC for fruit intake could not be estimated for the situations where the calculations include negative correlations between $\alpha$-carotene and fruit intake assessed by the 180-item FFQ, and between $\beta$ carotene and fruit intake (Table 4). Fruit intake has not been included in Tables 5, A1 and A2.

\section{Discussion}

In most validation studies data from one test method and one reference method are available, whereas in the present study we estimated fruit and vegetable intake from three dietary assessment methods and several biomarkers. This represents a major strength of the present study, and allows us to use the method of triad.

Table 5. Validity coefficients (VC) with $95 \%$ confidence intervals ${ }^{*}$ for fruit and vegetable intake estimated by the two food frequency questionnaires (FFQ) and the weighed records (WR) and serum $\alpha$-carotene as a biomarker for fruit and vegetables

\begin{tabular}{|c|c|c|c|c|c|c|}
\hline \multirow[b]{2}{*}{ Variable } & \multicolumn{3}{|c|}{ Vegetables } & \multicolumn{3}{|c|}{ Fruit and vegetables } \\
\hline & VC & $95 \% \mathrm{Cl}$ & $95 \% \mathrm{Cl} \dagger$ & VC & $95 \% \mathrm{Cl}$ & $95 \% \mathrm{Cl} \dagger$ \\
\hline \multicolumn{7}{|l|}{$\alpha$-Carotene $(n 100)$} \\
\hline WR - T & 0.77 & $0.58,1.00$ & $0.58,1.00$ & 0.79 & $0.52,1.00$ & $0,1.00$ \\
\hline 180-Item FFQ - T & 0.58 & $0.31,0.75$ & $0.31,0.75$ & 0.54 & $0.19,0.86$ & $0,0.86$ \\
\hline Serum concentration $-\mathrm{T}$ & 0.67 & $0.42,0.82$ & $0.42,0.82$ & 0.47 & $0.13,0.69$ & $0,0.69$ \\
\hline Missing $\ddagger$ & & 0 & & & $3.3 \%$ & \\
\hline \multicolumn{7}{|l|}{$\alpha$-Carotene $(n 86)$} \\
\hline$W R-T$ & 0.77 & $0.55,0.99$ & $0.55,0.99$ & 0.91 & $0.63,1.00$ & $0.60,1.00$ \\
\hline 27-Item FFQ - T & 0.51 & $0.31,0.70$ & $0.31,0.70$ & 0.60 & $0.27,0.91$ & $0.21,0.91$ \\
\hline Serum concentration $-\mathrm{T}$ & 0.69 & $0.46,0.89$ & $0.46,0.89$ & 0.43 & $0.14,0.66$ & $0.10,0.66$ \\
\hline Missing $\ddagger$ & & 0 & & & $1.1 \%$ & \\
\hline
\end{tabular}

$\mathrm{T}$, unknown true dietary intake.

* Validity coefficients and confidence limits $>1$ were set to 1.00

† Confidence interval when missing validity coefficients was set to zero.

‡Proportion of VC that could not be estimated because one of the three correlations that form the basis for the VC is negative. In this case the $\mathrm{VC}$ are set to missing values. 
To our knowledge this is the first study applying the method of triad to evaluate the validity of different assessment methods for intake of fruit and vegetables. The results indicate that a short FFQ gives as valid an estimate for fruit and vegetable intake as a long FFQ. Moreover, the VC suggest that serum $\alpha$-carotene is the best carotenoid biomarker for vegetable intake alone and for total intake of fruit and vegetables.

\section{Fruit and vegetable intake compared with serum carotenoid level}

Application of multiple dietary assessment methods makes it possible to base the validity of dietary intake on the relative magnitude of associations between methods rather than absolute magnitude. Only two studies have been published where fruit and vegetable estimates from multiple methods of dietary assessment were compared with serum carotenoid levels (Kristal et al. 2000; Resnicow et al. 2000). Assuming that higher correlations between dietary variables and serum levels can be interpreted as an indication of greater validity, it appears that the weighed records produced more valid estimates of fruit and vegetable than the 180- and twenty-seven item FFQ. These observations are not surprising because the weighed record is expected to give more accurate data than the FFQ. The 180-item FFQ did not seem to give more valid estimates than the twenty-seven item FFQ. Resnicow et al. (2000) observed that the validity of a thirty-six-item FFQ and a $3 \mathrm{~d}$ recall were generally stronger than the validity of two very short FFQ (seven-item and two-item).

In our study the strongest correlations were observed between serum concentration of $\alpha$-carotene and vegetable intake, and between serum $\alpha$-carotene and total vegetable and fruit intake. A possible explanation for this could be that the main source of $\alpha$-carotene intake in Norway is carrots, and carrots are the most eaten vegetable in this study and in the Norwegian population in general. Both the weighed record and the 180-item FFQ showed that about $30 \%$ of the total intake of vegetables was carrots. Moreover, controlled feeding studies have shown a proportional larger response in serum concentration of $\alpha$-carotene according to intake, than other carotenoids (Micozzi et al. 1992; Yeum et al. 1996; Brevik et al. 2004). The observed correlation coefficients for $\alpha$-carotene are in the same range as previously reported (correlations from 0.20 to 0.50) (Campbell et al. 1994; Michaud et al. 1998; Tucker et al. 1999; Resnicow et al. 2000; van Kappel et al. 2001). The correlations between serum $\beta$-carotene and vegetable intake, and $\beta$-carotene and total vegetable and fruit intake ranged from $0 \cdot 07$ to $0 \cdot 26$ for the three dietary survey methods. The highest correlation was observed between vegetable intake estimated from the weighed record and serum $\beta$-carotene, and this correlation was similar to what was observed in two other studies (Tucker et al. 1999; van Kappel et al. 2001). Other authors have presented correlations between 0.31 and 0.45 for fruit and vegetable intake and concentration of $\beta$-carotene in blood (Campbell et al. 1994; Resnicow et al. 2000; Block et al. 2001). No significant correlations were observed between fruit intake and any of the serum carotenoids in the present study, which is in contrast to findings by van Kappel et al. (2001). They observed correlation coefficients ranging from 0.21 to $0 \cdot 39$ between fruit intake assessed by a FFQ and serum concentration of four carotenoids $(\alpha$-carotene, $\beta$-carotene, lutein and $\beta$-cryptoxanthin). Fruit and vegetable intake from all three methods was generally uncorrelated with zeaxanthin and lycopene. The lack of association between vegetable intake and serum lycopene is consistent with several prior observations (Campbell et al. 1994; Martini et al. 1995; Resnicow et al. 2000) and may have multiple possible explanations. First, the most important food source for lycopene in the Norwegian diet is tomato and its products. However, tomato sauce used on pizza was not included in the vegetable intake estimated from the weighed record and the 180-item FFQ in the present study; this might explain the low diet-serum correlation. Second, the intake of tomato in our population is low. The average intake from the weighed record was 9 (SD 10) $\mathrm{g}$ from raw tomato and 6 (SD 8) $\mathrm{g}$ from tomato products (not including tomato sauce from pizza), and from the 180-item FFQ the intake was 4 (SD 5) g from raw tomato and 6 (SD 5) g from tomato products. No question about tomato intake was included in the twenty-seven item FFQ. Third, there is also some evidence that the bioavailability of lycopene is higher from heated tomato products than raw tomato (Johnson, 1998; van Het Hof et al. 2000). Thus, consumption of raw tomatoes may not be strongly reflected in serum carotenoid level. Another possible explanation could be a seasonal effect, this would especially have an effect when comparing the 180-item FFQ and serum lycopene because this FFQ reflects the usual intake whereas the measured serum lycopene may be a better measure of intake during autumn and winter. However, a nationwide survey in Norway from 1993-4 did not show variation in intake of tomato between the four seasons (Johansson et al. 1997).

The validity criterion used in our present study was serum carotenoid level. The serum values are subject to day-to-day fluctuations and individual variations (Tangney et al. 1987; Olmedilla et al. 1994; Cooney et al. 1995; Scott et al. 1996). Therefore the carotenoid level from a single blood sample may not be a valid measure of the usual intake. This type of error may attenuate the observed correlations between intake and biomarker. Especially, the correlations between intake from the 180-FFQ (aimed to measure the usual intake) and the biomarker could be attenuated by our study design. Moreover, the study design may favour the associations between biomarker and intake from the weighed records since the blood sample was collected close to the record period.

\section{The method of triads}

Estimated VC for the dietary assessment methods varied depending on the biomarker included in the calculations. The VC for vegetable intake estimated for the 180- and the twenty-seven item FFQ were relatively high (range from 0.41 to 0.58 ), except when $\beta$-carotene was included in the calculation. VC for the biomarkers were highest for $\alpha$-carotene as a marker for vegetable intake and as a marker for total intake of fruit and vegetables, whereas the $\mathrm{VC}$ for $\beta$-carotene, lutein and zeaxanthin were quite low. With two exceptions (vegetable, $\alpha$-carotene; Table 5) the $\mathrm{VC}$ for the dietary assessment methods were higher or similar to $\mathrm{VC}$ observed for the biomarkers. Although no comparable studies are available, Kabagambe et al. (2000) also found that $\mathrm{VC}$ for carotenoid intake estimated from a questionnaire were higher or similar to $\mathrm{VC}$ for the plasma carotenoids, which were their biomarkers. Daures et al. (2000) reported the opposite results; VC for $\beta$-carotene intake based on a FFQ, dietary records and plasma $\beta$-carotene were $0.39,0.52$ and 0.85 , respectively.

The estimation of confidence intervals for the VC performed well when the calculations involved $\alpha$-carotene as the biomarker (Table 5). Obviously, because $\mathrm{VC}$ are not defined for negative 
correlations, missing values will be relatively frequent in the bootstrapping when the calculations involve low estimated correlation coefficients (i.e. confidence intervals including 0). The empirical percentiles were found from distributions based on only $69-95 \%$ of the bootstrap samples in Tables A1 and A2, and our alternative confidence intervals, with missing estimates set to zero, illustrate the problem.

It is common to set estimated VC and confidence limits $>1.00$ to 1.00 (Ocke \& Kaaks, 1997; Daures et al. 2000; Kabagambe et al. 2000). VC values $>1$ indicate a strong relationship only if they are the result of random sampling errors. Violations of underlying model assumptions may also give $\mathrm{VC}$ values $>1$. The method of triads is based on an assumption that the errors associated with each of the three methods included in the model are independent, and that estimates from the FFQ, weighed records and biomarkers are linearly related to the common true intake. This may not be true, we cannot rule out that there exist correlated errors between the FFQ and the weighed record. Thus the reported VC could have been overestimated and should be regarded as upper limits of the true VC.

Another limitation of the present study may be the relatively small sample size and the homogeneity of the study population, in particular related to age and gender. There may be differences between men and women with regard to estimation of fruit and vegetables, which would require additional studies.

\section{Conclusion}

Our data show that the short FFQ gives as valid an estimate for total intake of fruit and vegetables as the long FFQ. Both the estimated partial correlation coefficients and the VC suggest that serum $\alpha$-carotene is the best biomarker for intake of vegetables alone and total intake of fruit and vegetables compared with any of the other carotenoids investigated in this study. Moreover, serum $\alpha$-carotene as a biomarker of vegetable intake seems to perform better than the FFQ, whereas serum $\alpha$-carotene as a biomarker for total fruit and vegetable intake did not perform better than the FFQs.

\section{Acknowledgements}

The authors thank Anne Randi Alvestad from the Department of Nutrition for expert technical assistance. The project was funded in part by the Norwegian Research Council, the Norwegian Nutrition Council and Throne Holst Foundation for Nutrition Research.

\section{References}

Andersen LF, Johansson L \& Solvoll K (2002) Usefulness of a short food frequency questionnaire for screening of low intake of fruit and vegetable and for intake of fat. Eur J Public Health 12, 208-213.

Andersen LF, Solvoll K, Johansson L, Salminen I, Aro A \& Drevon CA (1999) Evaluation of a food frequency questionnaire with weighed records, fatty acids and alpha-tocopherol in adipose tissue and serum. Am J Epidemiol 150, 75-87.

Blaker B \& Aarsland M (1989) Household Measures and Weight of Foods. Oslo: Landsforeningen for kosthold og helse.

Blaker B, Solvoll K \& Lund-Larsen K (1988) Dietary Data from the Municipality of Vestre Toten 1987. Results from 24h Recall Among Men and Women 30-59 Years Old, 6. Oslo: Section for Dietary Research, University of Oslo.
Block G, Norkus E, Hides M, Mandel S \& Helzlsouer K (2001) Which plasma antioxidants are most related to fruit and vegetable consumption. Am J Epidemiol 154, 1113-1118.

Bowen PE, Garg V, Stacewicz-Sapuntzakis M, Yelton L \& Schreiner RS (1993) Variability of serum carotenoids in response to controlled diets containing six servings of fruits and vegetables per day. Ann N Y Acad Sci 691, 241-243.

Brady WE, Mares-Perlman JA, Bowen P \& Stacewicz-Sapuntzalis M (1996) Human serum carotenoid concentrations are related to physiologic and lifestyle factors. J Nutr 126, 129-137.

Brevik A, Andersen LF, Karlsen A, Blomhoff R \& Drevon CA (2004) Six carotenoids in plasma used to assess recommended intake of fruit and vegetable intake in a controlled feeding study. Eur J Clin Nutr 58, 1166-1173.

Broekmanns WMR, Klöpping-Ketelaars IAA, Schuurman CRWC, Verhagen H, van den Berg H, Kok FJ \& van Poppel G (2000) Fruits and vegetables increase plasma carotenoids and vitamins and decrease homocysteine in human subjects. J Nutr 130, 1578-1583.

Brown ED, Micozzi MS, Craft NE, Bieri JG, Beecher G, Edwards BK, Rose A, Taylor PR \& Smith JC (1989) Plasma carotenoids in normal men after a single ingestion of vegetables or purified $\beta$-carotene. Am J Clin Nutr 49, 1258-1265.

Campbell DR, Gross MD, Martini MC, Slavin JL \& Potter JD (1994) Plasma carotenoids as biomarkers of vegetables and fruit intake. Cancer Epidemiol Biomark Prev 3, 493-500.

Cooney RV, Franke Aa, Hankin JH, Custer LJ, Wilkens LR, Harwood PJ \& Le Marchand L (1995) Seasonal variation in plasma micronutrients and antioxidants. Cancer Epidemiol Biomark Prev 4, 207-215.

Daures J-P, Gerber M, Scali J, Astre C, Bonifacj C \& Kaaks R (2000) Validation of a food-frequency questionnaire using multiple-day records and biochemical markers: application of the triads method. $J$ Epidemiol Biostatistics 5, 109-115.

De Angelis D \& Young GA (1998) Bootstrap method. In Encyclopedia of Biostatistics [P Armitage and T Colton, editors], pp. 426-433. Chichester: Wiley.

Forman MR, Beecher GR, Lanza E, Reichman ME, Graubard BI, Campbell WS, Marr T, Yong LC, Judd JT \& Taylor PR (1995) Effect of alcohol consumption on plasma carotenoid concentrations in premenopausal women: a controlled dietary study. Am J Clin Nutr 62, 131-135.

Fowke JH, Herbert JR \& Fahey JW (2002) Urinary excretion of dithiocarbamates and self-reported cruciferous vegetable intake: application of the 'method of triads' to a food-specific biomarker. Public Health Nutr 5, 791-799.

Jensen CD, Pattison TS, Spiller GA, Whittam JH \& Scala J (1985) Repletion and depletion of serum $\alpha$ - and $\beta$-carotene in human subjects with carrots and an algae-derived supplement. Acta Vitaminol Enzymol 7, 189-198.

Johansson L, Solvoll K, Opdahl S, Bjørneboe GE \& Drevon CA (1997) Response rates with different distribution methods and reward, and reproducibility of a quantitative food frequency questionnaire. Eur $J$ Clin Nutr 51, 346-353.

Johnson EJ (1998) Human studies on bioavailability and plasma response of lycopene. Proc Soc Exp Biol Med 218, 115-120.

Kaaks RJ (1997) Biochemical markers as additional measurements in studies of the accuracy of dietary questionnaire measurements: conceptual issues. Am J Clin Nutr 65, 1232S-1239S.

Kabagambe EK, Baylin A, Allan DA, Siles X, Spiegelman D \& Campos $\mathrm{H}$ (2000) Application of the method of triads to evaluate the performance of food frequency questionnaires and biomarkers as indicators of long-term dietary intake. Am J Epidemiol 154, 1126-1135.

Kim H \& Simphson KL (1988) Serum carotenoids and retinol of human subjects consuming carrot juice. Nutr Res 8, 1119-1127.

Kitamura Y, Tanaka K, Kiyohara C, Hirohata T, Tomita Y, Isibashi M \& Kido K (1997) Relationship of alcohol use, physical activity and dietary habits with serum carotenoids, retinol and alpha-tocopherol among male Japanese smokers. Int J Epidemiol 26, 307-314. 
Kristal AR, Vizenor NC, Patterson RE, Neuhouser ML, Shattuck AL \& McLerran D (2000) Precision and bias of food frequency-based measures of fruit and vegetable intakes. Cancer Epidemiol Biomark Prev 9, 939-944.

Martini MC, Campbell DR, Gross MD, Grandits GA, Potter JD \& Slavin JL (1995) Plasma carotenoids as biomarkers of vegetable intake: the University of Minnesota Cancer prevention Research Unit Feeding studies. Cancer Epidemiol Biomark Prev 4, 491-496.

Michaud DS, Giovannucci EL, Ascherio A, Rimm EB, Forman MR, Sampson L \& Willett WC (1998) Associations of plasma carotenoids concentrations and dietary intake of specific carotenoids in samples of two perspective cohort studies using a new carotenoid database. Cancer Epidemiol Biomark Prev 7, 283-290.

Micozzi MS, Brown ED, Edwards BK, Bieri BK, Taylor PR, Khachik F, Beecher GR \& Smith JC (1992) Plasma carotenoids responses to chronic intake of selected foods and $\beta$-carotene supplements in men. Am J Clin Nutr 49, 1258-1265.

Nes M, Andersen LF, Solvoll K, Sandstad B, Hustvedt BE, Løvø A \& Drevon CA (1992) Accuracy of a quantitative food frequency questionnaire applied in elderly Norwegian women. Eur J Clin Nutr 46, $809-821$

Ocke MC \& Kaaks RJ (1997) Biochemical markers as additional measurements in dietary validity studies: application of the method of triads with examples from the European Prospective Investigation into Cancer and Nutrition. Am J Clin Nutr 65, 1240S-1245S.

Olmedilla B, Granada F, Blanco I \& Rojas-Hidalgo E (1994) Seasonal and sex-related variations in six serum carotenoids, retinol, and $\alpha$-tocopherol. Am J Clin Nutr 60, 106-110.

Pufulete M, Emery PW, Nrlson M \& Sanders TAB (2002) Validation of a short food frequency questionnaire to assess folate intake. Br J Nutr 87 , 383-390

Resnicow K, Odom E, Wang T, Dudley WN, Mitchell D, Vaughan R, Jackson A \& Baranowski T (2000) Validation of three food frequency questionnaires and 24-hour recalls with serum carotenoid levels in a sample of African-American adults. Am J Epidemiol 152, 1072-1080.
Rock CL, Flatt SW, Wright FA, Faerber S, Newman V, Kealey S \& Pierce JP (1997) Responsiveness of carotenoids to a high vegetable diet intervention designed to prevent breast cancer recurrence. Cancer Epidemiol Biomark Prev 6, 617-623.

Scott KJ, Thurnham DI, Hart DJ, Bingham SA \& Day K (1996) The correlation between the intake of lutein, lycopene and $\beta$-carotene from vegetables and fruits, and blood plasma concentrations in a group of women aged 50-65 years in UK. Br J Nutr 75, 409-418.

Solvoll K, Løken EB, Grønn M \& Andersson E (1985) Dietary Data from the Municipality of Vestre Toten 1982. Results from 24h Recall Among Men and Women 25-54 Years Old, 2. Oslo: Section for Dietary Research, University of Oslo.

Statens ernæringsråd \& Statens næringsmiddeltilsyn (1995) Food Composition Table. Oslo: Gyldendal.

Tangney CC, Shekelle RB, Raynor W, Gale M \& Betz EP (1987) Intraand interindividual variation in measurements of $\beta$-carotene, retinol, and tocopherols in diet and plasma. Am J Clin Nutr 45, 764-769.

Tucker KL, Chen H, Vogel S, Wilson PWF, Schaefer EJ \& Lammi-Keefe CJ (1999) Carotenoid intakes, assessed by dietary questionnaire, are asssociated with plasma carotenoid concentrations in an elderly population. J Nutr 129, 438-445.

van Het Hof KH, De Boer BCJ, Tijburg LBM, Lucius BRHM, Zijp I, West CE, Hautvast JGAJ \& Westrate JA (2000) Carotenoid bioavailability in human subjects from tomatoes processed in different ways determined from the carotenoid response in the triglyceride-rich lipoprotein fraction of plasma after a single consumption and in plasma after four days of consumption. J Nutr 130, 1189-1196.

van Kappel AL, Steghens J, Zeleniuch-Jacquotte A, Chajes V, Toniolo P \& Riboli E (2001) Serum carotenoids as biomarkers of fruit and vegetable consumption in the New York Women's Health Study. Public Health Nutr 4, 829-835.

Yeum K, Booth SL, Sadowski JA, Jackson A, Tang G, Krinsky NI \& Russell RM (1996) Human plasma carotenoid response to the ingestion of controlled diet high in fruits and vegetables. Am J Clin Nutr 64, 594-602.

\section{Appendix}

Table A1. Validity coefficients (VC) with $95 \%$ confidence intervals* for fruit and vegetable intake estimated by the 180 -item food frequency questionnaire (FFQ) and the weighed records (WR) and by three biomarkers for fruit and vegetable intake $(n 100)$

\begin{tabular}{|c|c|c|c|c|c|c|}
\hline \multirow[b]{2}{*}{ Variable } & \multicolumn{3}{|c|}{ Vegetables } & \multicolumn{3}{|c|}{ Fruit and vegetables } \\
\hline & VC & $95 \% \mathrm{Cl}$ & $95 \% \mathrm{Cl} \dagger$ & VC & $95 \% \mathrm{Cl}$ & $95 \% \mathrm{Cl} \dagger$ \\
\hline \multicolumn{7}{|l|}{$\beta$-Carotene } \\
\hline$W R-T$ & 1.00 & $0.53,1.00$ & $0,1 \cdot 00$ & 1.00 & $0.26,1.00$ & $0,1.00$ \\
\hline 180-Item FFQ - T & 0.38 & $0.10,0.89$ & $0,0.84$ & 0.41 & $0.11,1.00$ & $0,1.00$ \\
\hline $\begin{array}{l}\text { Serum concentration }-\mathrm{T} \\
\text { Missingf }\end{array}$ & 0.22 & $\begin{array}{c}0.05,0.47 \\
28.9 \%\end{array}$ & $0,0.49$ & 0.18 & $\begin{array}{c}0.03,0.42 \\
30.6 \%\end{array}$ & $0,0.41$ \\
\hline \multicolumn{7}{|l|}{ Lutein } \\
\hline WR $-\mathrm{T}$ & 0.86 & $0.36,1.00$ & $0,1 \cdot 00$ & 0.78 & $0.42,1.00$ & $0,1.00$ \\
\hline 180-Item FFQ - T & 0.52 & $0.15,1.00$ & $0,1 \cdot 00$ & 0.55 & $0.21,1.00$ & $0,0.99$ \\
\hline Serum concentration $-\mathrm{T}$ & 0.25 & $0.05,0.49$ & $0,0.49$ & 0.29 & $0.07,0.52$ & $0,0.52$ \\
\hline Missingł & & $11.5 \%$ & & & $6.8 \%$ & \\
\hline \multicolumn{7}{|l|}{ Zeaxanthin } \\
\hline$W R-T$ & 0.79 & $0.26,1.00$ & $0,1.00$ & 0.62 & $0.25,1.00$ & $0,1.00$ \\
\hline 180-Item FFQ - T & 0.56 & $0.19,1.00$ & $0,1.00$ & 0.68 & $0.30,1.00$ & $0,1.00$ \\
\hline Serum concentration $-\mathrm{T}$ & 0.18 & $0.03,0.41$ & $0,0.40$ & 0.25 & $0.06,0.49$ & $0,0.49$ \\
\hline Missingł & & $14.8 \%$ & & & $5.4 \%$ & \\
\hline
\end{tabular}

T, unknown true dietary intake.

*Validity coefficients and confidence limits $>1$ were set to 1.00 .

$\dagger$ Confidence interval when missing validity coefficient was set to zero.

¥Proportion of VC that could not be estimated because one of the three correlations that form the basis for the VC is negative. In this case the VC are set to missing values. 
Table A2. Validity coefficients (VC) with $95 \%$ confidence intervals* for fruit and vegetable intake estimated by the 27-item food frequency questionnaire (FFQ) and the weighed records (WR) and by three biomarkers for fruit and vegetable intake $(n 86)$

\begin{tabular}{|c|c|c|c|c|c|c|}
\hline \multirow[b]{2}{*}{ Variable } & \multicolumn{3}{|c|}{ Vegetables } & \multicolumn{3}{|c|}{ Fruit and vegetables } \\
\hline & VC & $95 \% \mathrm{Cl}$ & $95 \% \mathrm{Cl} \dagger$ & VC & $95 \% \mathrm{Cl}$ & $95 \% \mathrm{Cl}+$ \\
\hline \multicolumn{7}{|l|}{$\beta$-Carotene } \\
\hline$W R-T$ & 1.00 & $0.39,1.00$ & $0,1.00$ & 0.96 & $0.49,1.00$ & $0,1.00$ \\
\hline 27-Item FFQ - T & 0.33 & $0.11,1.00$ & $0,0.96$ & 0.57 & $0.17,1.00$ & $0,1 \cdot 00$ \\
\hline Serum concentration $-T$ & 0.21 & $0.05,0.52$ & $0,0.51$ & 0.21 & $0.04,0.47$ & $0,0.47$ \\
\hline Missing $\ddagger$ & & $25 \cdot 1 \%$ & & & $11.5 \%$ & \\
\hline \multicolumn{7}{|l|}{ Lutein } \\
\hline$W R-T$ & 0.93 & $0.40,1.00$ & $0,1.00$ & 0.90 & $0.51,1.00$ & $0,1.00$ \\
\hline 27-Item FFQ - T & 0.42 & $0.12,0.94$ & $0,0.91$ & 0.60 & $0.25,1.00$ & $0,1 \cdot 00$ \\
\hline Serum concentration $-\mathrm{T}$ & 0.24 & $0.05,0.55$ & $0,0.54$ & 0.27 & $0.05,0.52$ & $0,0.52$ \\
\hline Missing $\ddagger$ & & $14 \cdot 2 \%$ & & & $8.4 \%$ & \\
\hline \multicolumn{7}{|l|}{ Zeaxanthin } \\
\hline$W R-T$ & 0.95 & $0.39,1.00$ & $0,1.00$ & 0.90 & $0.49,1.00$ & $0,1.00$ \\
\hline 27-Item FFQ - T & 0.41 & $0.12,0.92$ & $0,0.88$ & 0.61 & $0.23,1.00$ & $0,1.00$ \\
\hline Serum concentration $-\mathrm{T}$ & 0.20 & $0.04,0.50$ & $0,0.49$ & 0.25 & $0.06,0.49$ & $0,0.49$ \\
\hline Missing $\ddagger$ & & $18 \cdot 9 \%$ & & & $8.4 \%$ & \\
\hline
\end{tabular}

T, unknown true dietary intake.

*Validity coefficients and confidence limits $>1$ were set to 1.00 .

† Confidence interval when missing validity coefficient was set to zero.

‡Proportion of VC that could not be estimated because one of the three correlations that form the basis for the VC is negative. In this case the VC are set to missing values. 